\title{
Validation of a calf-side $\beta$-hydroxybutyrate test and its utility for estimation of starter intake in dairy calves around weaning
}

\author{
S. M. Deelen, ${ }^{*}$ K. E. Leslie, ${ }^{*}$ M. A. Steele, $†$ E. Eckert, $\ddagger$ H. E. Brown, $\ddagger$ and T. J. DeVries $\ddagger^{1}$ \\ *Department of Population Medicine, University of Guelph, Guelph, Ontario, N1G 2W1 Canada \\ †Department of Agricultural, Food and Nutritional Science, University of Alberta, Edmonton, Alberta, T6G 2P5 Canada \\ ‡Department of Animal Biosciences, University of Guelph, Guelph, Ontario, N1G 2W1 Canada
}

\section{ABSTRACT}

Recent research suggests that circulating $\beta$-hydroxybutyrate (BHB) levels may be a meaningful indicator of grain intake and rumen development in pre-ruminant calves. As such, BHB levels may be a surrogate measure of rumen function to contribute to minimal weaning stress during the transition from liquid to solid feed. The primary objective of this study was to determine the optimal cut-point of circulating BHB levels that would be predictive of sufficient grain intake and rumen development for a successful transition from liquid to solid feed at the time of weaning. An additional objective was to validate the Precision Xtra (Abbott Diabetes Care, Abingdon, UK) calf-side test for determination of BHB in whole blood in calves around weaning, as compared with the gold standard laboratory method. A total of 20 Holstein female calves were randomly assigned at birth to be weaned at $6 \mathrm{wk}$ $(\mathrm{n}=10)$ or $8 \mathrm{wk}(\mathrm{n}=10)$ of age. Milk replacer (mixed at $150 \mathrm{~g} / \mathrm{L}$ ) was offered at $1.2 \mathrm{~kg} /$ calf per d in 2 meals until a 1-wk step down, when milk meals were reduced by $50 \% 1$ wk before weaning. Daily measurements included the intakes of starter grain, chopped straw, and water. Weekly measurements included body weight and blood BHB, until $70 \mathrm{~d}$ of life. To assess digestive tract development, rumen fluid samples were taken before and after weaning (d 35, 49, and 63) and analyzed for ruminal short-chain fatty acids. Whole blood was collected by jugular venipuncture, and BHB was determined by the Precision Xtra test at calf-side. In addition, serum was separated from a clotted sample, frozen, and stored until laboratory analysis was performed. Laboratory BHB results were correlated with both the Precision Xtra test $(\mathrm{r}=0.95)$ and starter intake over $1 \mathrm{~d}(\mathrm{r}=0.89)$, a 3 -d average $(\mathrm{r}=0.90)$, and a 7 -d average $(\mathrm{r}=0.90)$. Additionally, laboratory BHB

Received February 26, 2016.

Accepted May 15, 2016.

${ }^{1}$ Corresponding author: tdevries@uoguelph.ca results were associated with total ruminal volatile fatty acids $(\mathrm{r}=0.82)$, ruminal butyrate $(\mathrm{r}=0.77)$, and body weight $(r=0.69)$. A receiver operating characteristic curve was created to plot the true positive rate against the false positive rate at $10 \mu \mathrm{mol} / \mathrm{L} \mathrm{BHB}$ intervals to determine the optimal cut-point of circulating BHB that is predictive of an average starter intake of 1,000 $\mathrm{g} / \mathrm{d}$ over a 3 -d period. The optimal combination of sensitivity (95.7\%) and specificity (96.1\%) was at 100 $\mu \mathrm{mol}$ of $\mathrm{BHB} / \mathrm{L}$ of blood. A value of $0.2 \mathrm{mmol} / \mathrm{L}$ on the Precision Xtra test yielded a sensitivity and specificity of 84.0 and $97.2 \%$, respectively, over the 3 -d average period of starter intake. These results show considerable promise for use of the Precision Xtra whole blood BHB test in the decision-making process of determining sufficient starter grain intake and rumen development for a successful transition from liquid to solid feed, and indicate that this test conducted at calf-side is highly accurate.

Key words: $\beta$-hydroxybutyrate, weaning, diagnostic test, dairy calf

\section{INTRODUCTION}

Among the most dramatic and important physiological challenges that young dairy calves will experience are the events surrounding the development of the rumen, as it is physically underdeveloped and metabolically nonfunctional at birth (Warner et al., 1956). In the neonate, the rumen does not exhibit the rumen papillae development and epithelial maturation and high degree of keratinization evident in the mature organ (Gilliland et al., 1962). Metabolically, it is essentially nonfunctional with respect to ketogenic capacity (Warner et al., 1956). Calves rely, for maintenance and growth, on the nutrients obtained from milk during the first few weeks of life. Inoculation and establishment of the anaerobic ruminal microbial ecosystem, initiation of starter feed consumption, as well as fermentation processes, are needed to trigger rumen development (Williams and Frost, 1992; Baldwin et al., 2004). Changes must also occur at the hepatic level to allow calves to 
make use of fermentation end products for maintenance and growth (Baldwin et al., 2004; Drackley, 2008). As calves progress from the neonatal consumption of milk to the consumption of a diet consisting of grain and forages, the reticulorumen develops into a functional organ where anaerobic fermentation of those dietary components occurs (Benschop and Cant, 2009).

Ruminal fermentation starts at a very young age, and VFA concentrations increase with increasing solid feed intake (Khan et al., 2016). As rumen development ensues, the epithelial surface area for VFA absorption increases through cell proliferation, and muscle layers thicken to facilitate mixing and eructation contractions (Khan et al., 2016). The microbial population in the rumen ferments carbohydrates into VFA, which include acetate, butyrate, and propionate. These VFA are the main energy source for ruminant animals (Brown et al., 1960). Butyrate, which is the most bioactive VFA, is absorbed by the ruminal epithelium and oxidized into ketones (Leighton et al., 1983; Lane et al., 2000; Baldwin et al., 2004; Khan et al., 2016). Quigley et al. (1991) suggests that one of these ketones, BHB, may be used as an indicator of rumen epithelium maturation and its ability to use VFA produced by the fermentation of solid feeds by the rumen microflora. The time course of this development is dependent in large part upon the age of the calf (Lane et al., 2002). A recent study looked at weaning age effects on growth, feed intake, gastrointestinal development, and behavior in Holstein calves fed an elevated plane of nutrition during the preweaning stage (Eckert et al., 2015). In both treatment groups, it was found that weaning was associated with increased ruminal short-chain fatty acids and blood BHB. However, the differences between the week before and the week after weaning were greater for calves weaned at $6 \mathrm{wk}$ compared with those weaned at 8 wk of age. Nemati et al. (2015) determined that the increasing blood BHB concentration that occurred as calves aged was mainly due to a shift in the sources of physiological fuel during the transition from liquid to solid diets. Additionally, Omidi-Mirzaei et al. (2015) evaluated pre-weaning calf nutrition programs, and have used blood BHB concentration as an outcome measure for the state of rumen development and readiness of the calves to transition to solid feed. A smooth transition from liquid feed (milk or milk replacer) to solid feed (grains or forage) is important to minimize weight loss and distress at weaning (Weary et al., 2009).

In human medicine, electronic handheld blood glucose and ketone measuring systems are widely used for diabetes monitoring (Guerci et al., 2005). A first report using an electronic human BHB meter (MediSense Precision, Abbott, Abingdon, UK) for dairy cows de- scribed a high correlation $\left(\mathrm{r}^{2}=0.99\right)$ with BHB concentrations determined spectrophotometrically (the gold standard laboratory test) and considered the test to be suitable for detecting subclinical ketosis in dairy cows (Jeppesen et al., 2006). An electronic patient-side test for measuring whole-blood BHB concentration (Precision Xtra, Abbott Diabetes Care, Abingdon, UK) was recently validated for use in dairy cows (Iwersen et al., 2009; Mahrt et al., 2014) and sheep (Panousis et al., 2012). The main advantages of the Precision Xtra test include an immediate quantitative measurement with high sensitivity and specificity, without logistical efforts for laboratory analysis (e.g., cooling, centrifugation, or shipping). Furthermore, this test was recently assessed for its ability to measure BHB in serum and plasma (Pineda and Cardoso, 2015). The use of this instrument as an indicator of rumen development in pre-ruminant calves has not been previously studied. As such, the objectives of the present study were to (1) determine the optimal cut-point of circulating BHB levels as a surrogate measure of grain intake and rumen development, and (2) validate the Precision Xtra test for BHB against the gold standard laboratory method in calves around weaning.

\section{MATERIALS AND METHODS}

\section{Calf Enrollment and Housing}

Twenty Holstein heifer calves from Eckerlea Acres Dairy Farm (Seaforth, ON, Canada) were sampled from June through August 2013. These calves were part of a larger study (Eckert et al., 2015) focused on determining the effect of weaning age on intake, growth, and behavior. As described in detail by Eckert et al. (2015), calves were randomly assigned at birth to be weaned at $6 \mathrm{wk}(\mathrm{n}=10)$ or $8 \mathrm{wk}(\mathrm{n}=10)$ of age. Detailed descriptions of the calving facilities, colostrum management, calf nursery barn, bedding type and management, feeding utensils, as well as the neonatal therapy and care are found in Eckert et al. (2015). This study was approved by Nutreco Canada's Agresearch (Guelph, ON, Canada) Animal Care Committee, and performed according to the guidelines of the Canadian Council on Animal Care (CCAC, 2009).

\section{Milk, Starter, Chopped Straw, and Water Feeding}

All calves were provided colostrum and then subsequently fed a milk replacer solution twice daily (0730 and $1630 \mathrm{~h}$ ) by nipple bottle (Super Calf Nipple, Merrick's, Middleton, WI). At $7 \pm 3$ d of age, calves were transitioned to a feeding system with a gate-mounted 
artificial teat (Peach Teats, Skellerup Industries Ltd., Woolston, New Zealand), by which they were fed until weaning. The artificial teat feeding setup consisted of the teat mounted at the front of the pen, which was attached to a tube, fitted with a one-way valve, which delivered the milk from an 8-L bucket placed outside the pen (similar to that described by Miller-Cushon et al., 2013). The bucket was replenished with $4 \mathrm{~L}$ of milk replacer twice daily. Also, once daily in the morning, after feeding, all buckets, lines, and teats were cleaned.

The milk replacer powder used for the study was Shur-Gain Optivia High Performance $(26 \%$ CP, $16 \%$ fat; $\mathrm{ME}=4.58 \mathrm{Mcal} / \mathrm{kg}$ ) Milk Replacer (Nutreco Canada Inc., Guelph, ON, Canada), mixed at a rate of $150 \mathrm{~g}$ to $1 \mathrm{~L}$ of $40^{\circ} \mathrm{C}$ water. Milk replacer was prepared at each feeding in sufficient volume to feed all calves. From birth to d 70 , pelleted calf starter $(22 \%$ CP; $\mathrm{ME}=2.63 \mathrm{Mcal} / \mathrm{kg})$, oat straw $(8 \% \mathrm{CP} ; \mathrm{ME}=1.55$ Mcal $/ \mathrm{kg}$ ) chopped to a length of $3 \mathrm{~cm}$, and water were provided ad libitum. Daily, at 0900 h, orts of starter, straw, and water were weighed and discarded, and fresh amounts were provided. Additional starter, straw, and water were added throughout the day and recorded, if necessary, to ensure continuous availability to the calves.

\section{Experimental Design, Intakes, and Sampling}

Calves were offered $6 \mathrm{~L}$ from $\mathrm{d} 1$ to $3,7 \mathrm{~L}$ from $\mathrm{d}$ 4 to 6 , and $8 \mathrm{~L}$ from $\mathrm{d} 7$ until their respective time of step-down weaning. The 6 -wk group was stepped down to $4 \mathrm{~L} / \mathrm{d}$ on $\mathrm{d} 36$ and weaned on $\mathrm{d} 43$. The 8 -wk group was stepped down to $4 \mathrm{~L} / \mathrm{d}$ on $\mathrm{d} 50$ and weaned on d 57. Intakes of starter, straw, and water were recorded daily at $0900 \mathrm{~h}$. Intake of milk replacer was recorded twice daily at each feeding. Calves were weighed at the same time of day $(1100 \mathrm{~h})$ weekly $( \pm 1 \mathrm{~d})$ starting at birth until d 70 .

Blood was collected from calves at 10 different time points throughout the study period, including at $\mathrm{d} 7$ $( \pm 1 \mathrm{~d})$, and every week thereafter to $\mathrm{d} 70$, by jugular venipuncture using a 20-gauge, 1 -inch $(2.54 \mathrm{~cm})$ hypodermic needle (BD Vacutainer Precision Glide, Becton Dickinson and Co., Franklin Lakes, NJ), into a sterile, plastic Vacutainer tube without anticoagulant (BD Vacutainer, Becton Dickinson and Co.). Additionally, a sample was collected mid-week on wk 6 and 8. Blood was always collected at $1100 \mathrm{~h}$. Immediately following collection, whole blood BHB was determined by the Precision Xtra test (Abbott Diabetes Care, Abingdon, $\mathrm{UK})$ at calf-side. Whole blood samples $(6 \mathrm{~mL})$ were stored at room temperature for 30 min before centrifu- gation at $1,500 \times g$ for $15 \mathrm{~min}$ at $\sim 20^{\circ} \mathrm{C}$. At 6 of the sampling times (wk 5,6,7,8,9, and 10), serum was separated and stored at $-20^{\circ} \mathrm{C}$ until laboratory analysis for BHB at the University of Guelph Animal Health Laboratory (Guelph, ON, Canada) using spectrophotometry, as described by Williamson et al. (1962).

To characterize digestive tract development before and after weaning, rumen fluid was collected, at 1100 $\mathrm{h}$, on d 35, 49, and 63 ( $\pm 1 \mathrm{~d})$, as described by Eckert et al. (2015).

\section{Statistical Analysis}

Serum BHB concentrations determined in the laboratory were regarded as the gold standard. Comparisons were performed between the Precision Xtra, starter intake, and BW results, and the laboratory BHB determinations for all samples. For ruminal fluid, one individual calf's sample (from wk 9) was missing, and thus not considered in the data set. The Precision Xtra $(\mathrm{mmol} / \mathrm{L})$ results, starter intake $(\mathrm{g} / \mathrm{d})$, and $\mathrm{BW}(\mathrm{kg})$ were plotted against the measured laboratory BHB content $(\mu \mathrm{mol} / \mathrm{L})$ and fitted with a linear function using Microsoft Excel (Microsoft Corp., Redmond, WA). Similarly, laboratory BHB content $(\mu \mathrm{mol} / \mathrm{L})$ was plotted against the ruminal fluid (total VFA, butyrate, propionate, and acetate) results $(\mu M)$; these associations were best fit with an exponential function. Statistical significance of all of these associations was then modeled using the REGRESSION procedure in SAS (SAS Institute Inc., 2013).

Using an arbitrary level of starter intake $(\geq 1,000$ $\mathrm{g} / \mathrm{d}$ ) to indicate meaningful rumen function (Drackley, 2008), test characteristics (sensitivity and specificity) of the laboratory BHB test, and of the Precision Xtra test, were calculated using Microsoft Excel 2010. Starter intake was measured over $1 \mathrm{~d}$ (the day the blood sample was drawn), a 3 -d average period ( $2 \mathrm{~d}$ before the blood sample was drawn, as well as the day the sample was drawn), and a 7-d average period ( $6 \mathrm{~d}$ before the blood sample was drawn, as well as the day the sample was drawn). Sensitivity was calculated as the proportion of calves with a starter intake of $\geq 1,000 \mathrm{~g} / \mathrm{d}$ correctly diagnosed as positive by the test. Specificity was calculated as the proportion of calves with a starter intake of $<1,000 \mathrm{~g} / \mathrm{d}$ correctly diagnosed as negative by the test. A receiver operating characteristic curve was created to plot the true positive rate against the false positive rate for the laboratory BHB test at $10 \mu \mathrm{mol} / \mathrm{L}$ intervals, from 40 to $190 \mu \mathrm{mol}$ of $\mathrm{BHB} / \mathrm{L}$ of blood, to determine the optimal cut-point of circulating BHB over a 3 -d average period of starter intake. 


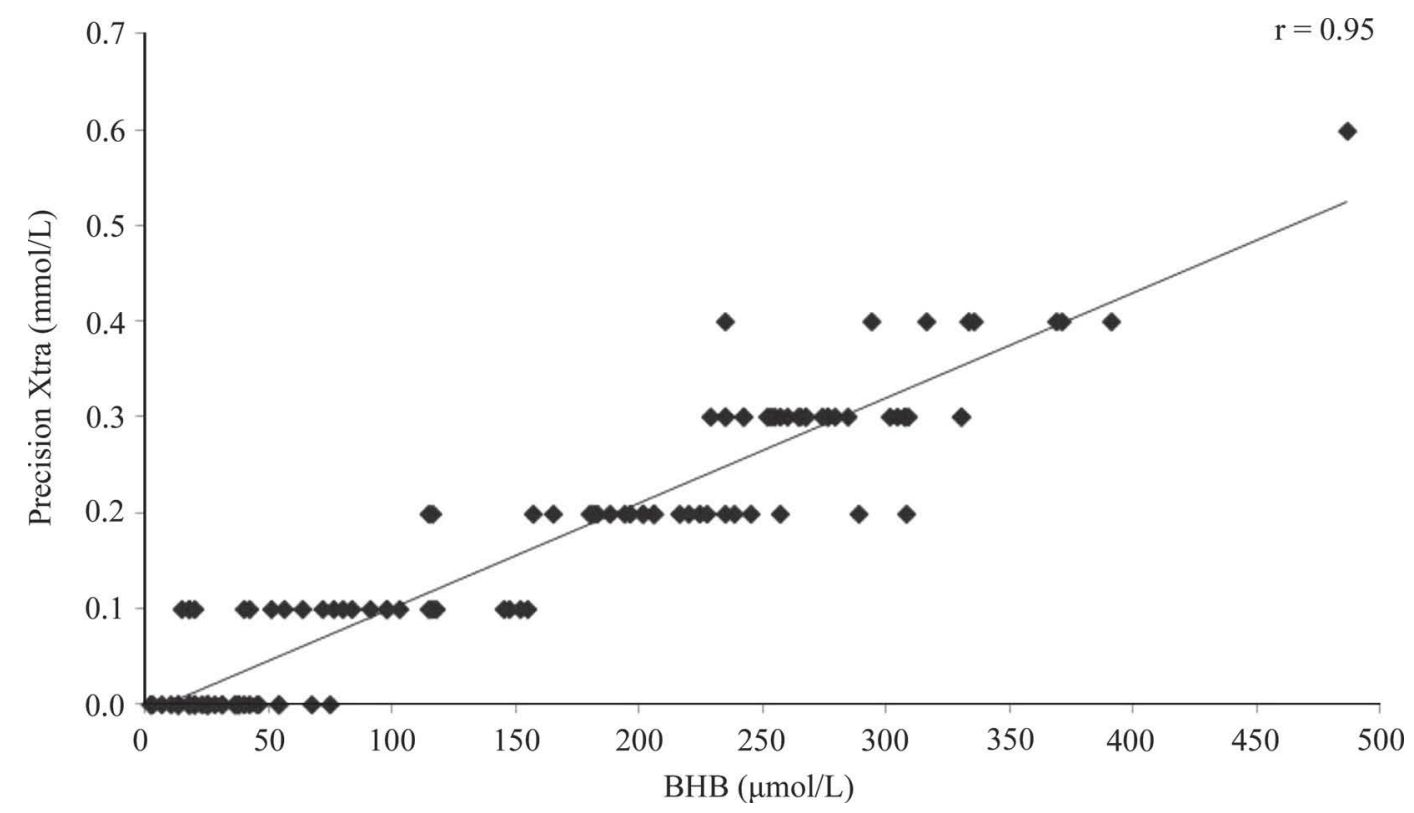

Figure 1. Circulating whole-blood BHB concentration as determined by the Precision Xtra (Abbott Diabetes Care, Abingdon, UK) test compared with the gold standard laboratory method $(\mathrm{n}=120)$.

\section{RESULTS AND DISCUSSION}

\section{Validation of the Precision Xtra Test}

The distribution of Precision Xtra versus laboratory BHB for all 120 samples analyzed is plotted in Figure 1. Laboratory BHB results were correlated with the Precision Xtra test $(\mathrm{r}=0.95 ; P<0.001)$. These results are comparable to the correlations reported in the early evaluation of the Precision Xtra test for the determination of BHB in whole blood of lactating cows, as compared with the determination of BHB in serum by the gold standard laboratory method (Iwersen et al., 2009; Mahrt et al., 2014). Thus, the results of the current study provide support for the use of the Precision Xtra test as a calf-side test for BHB levels.

\section{Correlation of Blood BHB with Starter Intake, Ruminal VFA, and BW}

The distribution of starter intake versus laboratory BHB for the 120 samples analyzed is plotted in Figure 2. Laboratory BHB results were linearly associated with starter intake measured on the day of sampling ( $\mathrm{r}$ $=0.89 ; P<0.001 ;$ Figure 2a), a 3 -d average including the day of sampling, which was $2 \mathrm{~d}$ before the blood sample was drawn, as well as the day the sample was drawn $(\mathrm{r}=0.90 ; P<0.001$; Figure $2 \mathrm{~b})$, and a 7 -d average including the day of sampling, which was $6 \mathrm{~d}$ before the blood sample was drawn, as well as the day the sample was drawn $(\mathrm{r}=0.90 ; P<0.001$; Figure $2 \mathrm{c})$. These results suggest that most of the increase in BHB was associated with calves increasing their intake of starter, and the subsequent increase in fermentation of substrate in the rumen. The current study also revealed similar levels of blood BHB associated with comparable levels of starter grain intake as in previously published works (Khan et al., 2011; Omidi-Mirzaei et al., 2015; Overvest et al., 2016).

The associations of laboratory BHB versus ruminal VFA for the 59 samples analyzed were best described with an exponential function. The association of laboratory BHB results with total ruminal VFA are described in Figure 3a $(\mathrm{r}=0.82 ; P<0.001)$ and with ruminal butyrate in Figure 3b $(\mathrm{r}=0.77 ; P<0.001)$. Similar associations of laboratory BHB results were seen with ruminal propionate $(\mathrm{r}=0.84 ; P<0.001)$ and ruminal acetate $(\mathrm{r}=0.76 ; P<0.001$; data not shown). A positive association between blood BHB and ruminal VFA, in particular butyrate, are expected as the increase in ruminal substrate can be expected to increase ketone body synthesis in the rumen epithelium (Lane et al., 2002). It should be noted, that given the exponential association, these results not only provide further support that blood BHB can be used as a marker of ruminal VFA production, but also that ruminal VFA concentration needs to reach a certain level before absorption is noticeable. Whereas VFA absorption from the rumen has been studied extensively in mature cows, with ruminal VFA concentration being one significant 

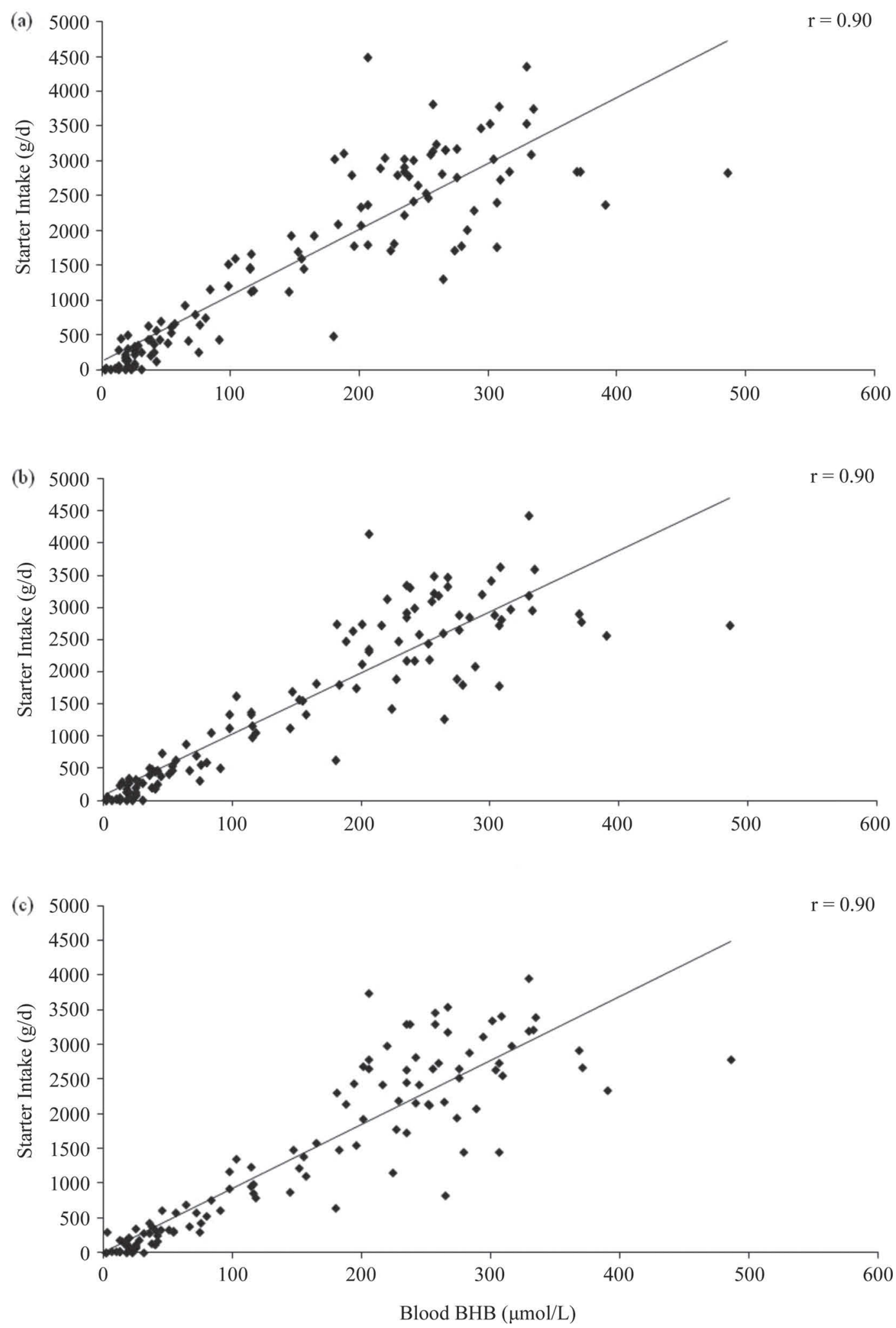

Figure 2. Starter intake measured over (a) $1 \mathrm{~d}(\mathrm{n}=120)$, (b) a 3-d average $(\mathrm{n}=120)$, and $(\mathrm{c})$ a 7 -d average $(\mathrm{n}=120)$, compared with circulating whole-blood BHB concentration as determined by the gold standard laboratory method. 

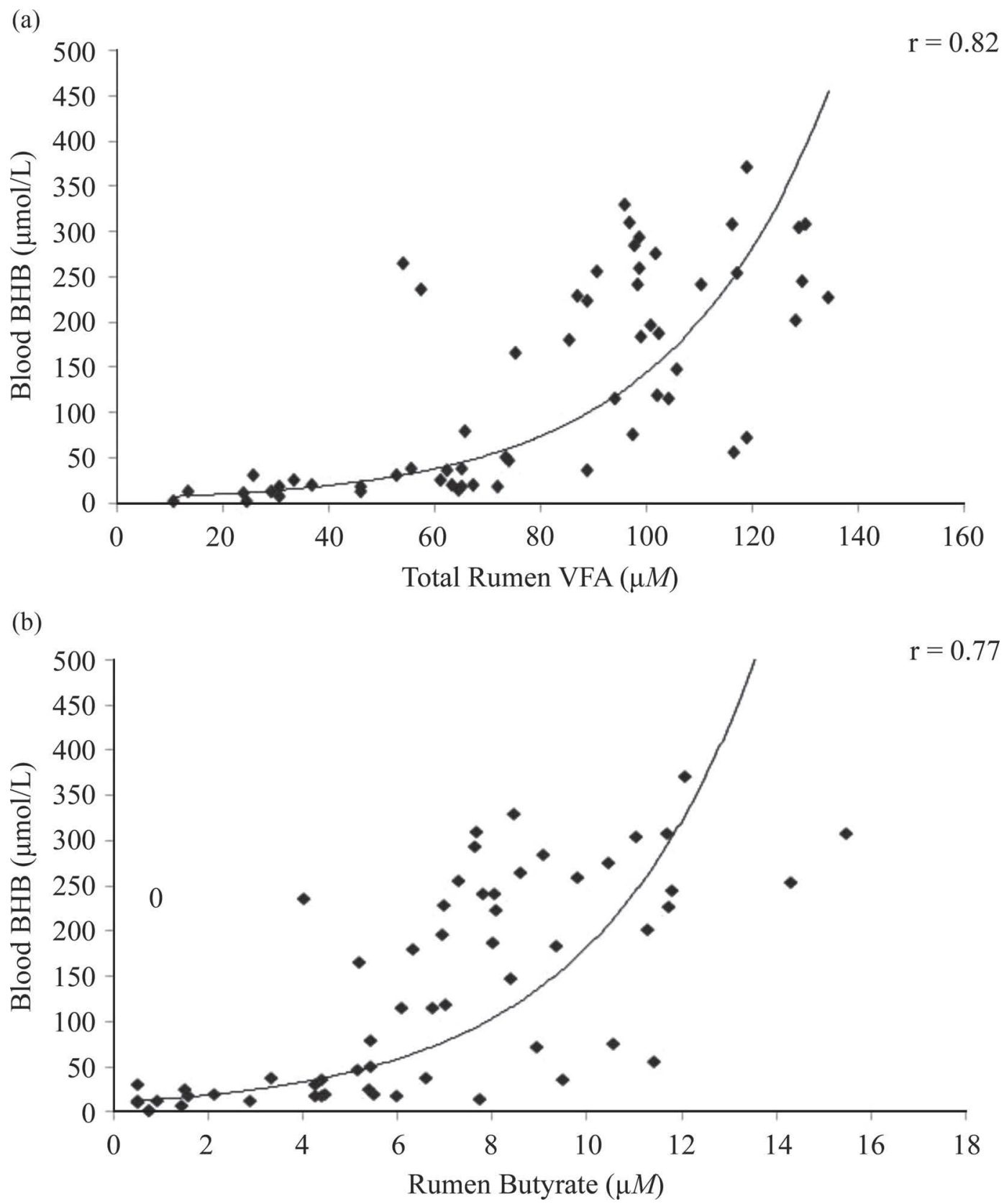

Figure 3. Circulating whole-blood BHB concentration as determined by the gold standard laboratory method compared with (a) total ruminal VFA $(\mathrm{n}=59)$ and $(\mathrm{b})$ ruminal butyrate $(\mathrm{n}=59)$.

contributor to those absorption rates (Dijkstra et al., 1993; Bannink et al., 2008), less research has been done on this for young dairy calves. As demonstrated by the current data, and suggested by Steele et al. (2012) in research on dairy cows, increased concentrations of circulating BHB likely reflect a mass action effect of increased substrate for rumen epithelium ketogenesis. In our study, the blood BHB levels in calves started to increase rapidly at ruminal butyrate concentrations at about 6 to $8 \mu M$ (Figure $3 \mathrm{~b}$ ), which is reflective of consumption of approximately 0.5 to $1.0 \mathrm{~kg} / \mathrm{d}$ of starter (Figure 2).

Similar to starter consumption, there was also a linear association between laboratory BHB results and calf BW ( $\mathrm{r}=0.69 ; P<0.001 ;$ Figure 4$)$. These findings provide further evidence that as the study calves were consuming increasing amounts of solid feed and growing throughout the study period (Eckert et al., 2015), more VFA were being absorbed and oxidized into ketones, providing energy to the animals for growth. In all, 


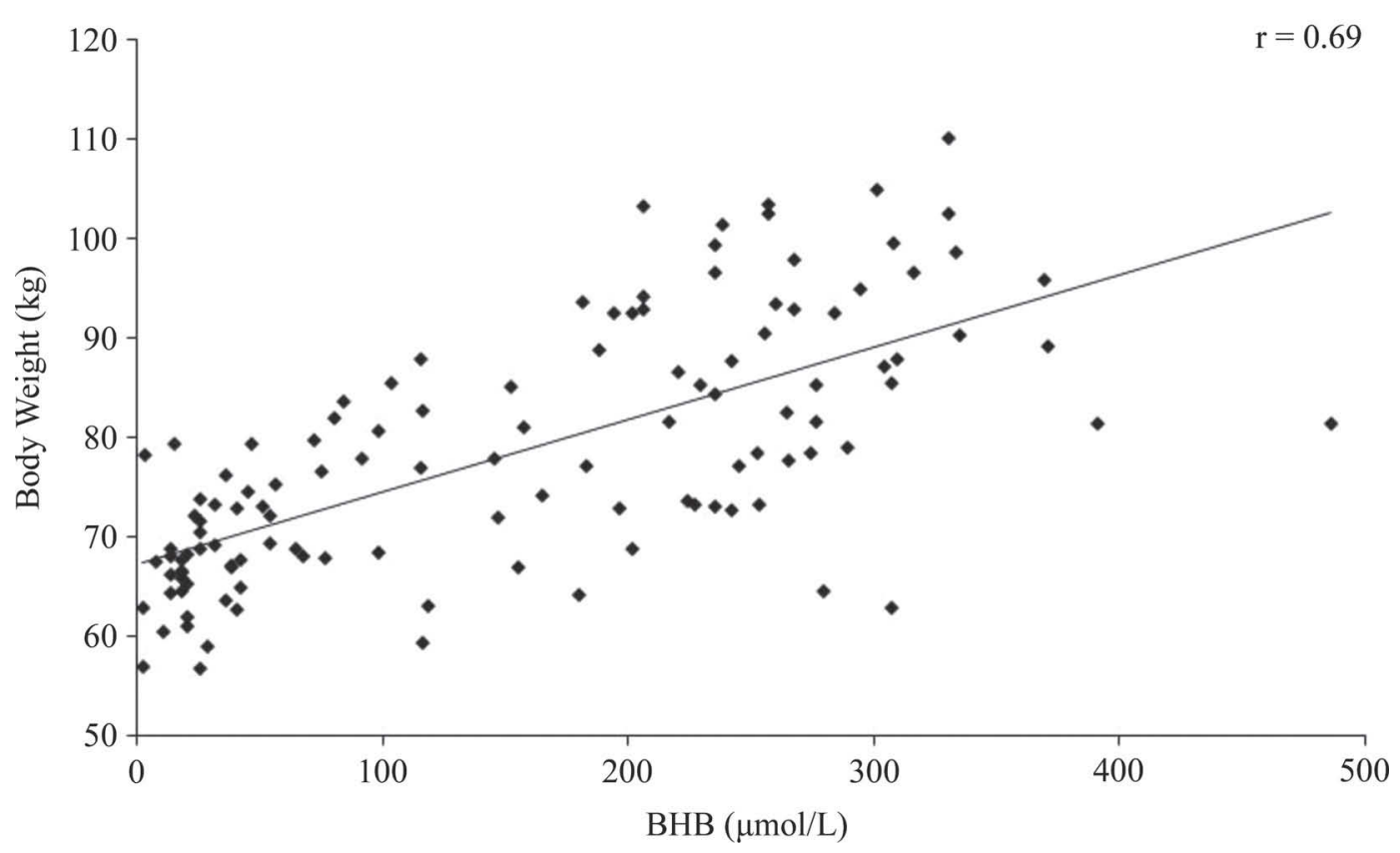

Figure 4. Body weight compared with circulating whole-blood BHB concentration as determined by the gold standard laboratory method $(\mathrm{n}=120)$.

these results provide support that the observed levels of blood BHB are reflective of the amount of butyrate that is being converted in the rumen epithelium, and not of that produced in the liver. It is possible that in a situation where calves are in a state of negative energy balance (e.g., extended period of low nutrient intake, whether from milk, solid feed, or both), the measurement of blood BHB may actually be a reflection of the $\mathrm{BHB}$ produced in the liver. To our knowledge, no work has compared the differential rates of BHB production (i.e., from the rumen epithelium or the liver) for calves consuming varied amount of nutrients and, thus, under different states of energy balance. As such, further work in this area is necessary.

\section{Determining Optimal Cut-Point of Circulating BHB for Weaning}

Test characteristics of sensitivity and specificity for laboratory BHB were determined for the assessment of adequate starter intake ( $\geq 1,000 \mathrm{~g} / \mathrm{d}$; Drackley, 2008), indicative of appropriate weaning age (Table 1). For these calculations, specificity was the test characteristic that needed to be maximized when determining the best combination of the 2 because false positives were of greater concern. Although the test may be reading an adequate level of BHB, if starter intake is less than $1,000 \mathrm{~g} / \mathrm{d}$, it is unlikely that the calf is consuming sufficient starter grain intake to promote the rumen devel- opment necessary to successfully transition from liquid to solid feed (Drackley, 2008). A receiver operating characteristic curve was created to plot the true positive rate against the false positive rate at $10 \mu \mathrm{mol} / \mathrm{L}$ intervals, from 40 to $190 \mu \mathrm{mol}$ of $\mathrm{BHB} / \mathrm{L}$ of blood, over the 3 -d average period of starter intake around the day of sampling (Figure 5). The best combination of sensitivity $(95.7 \%)$ and specificity $(96.1 \%)$ was at $100 \mu \mathrm{mol}$ of $\mathrm{BHB} / \mathrm{L}$ of blood. Receiver operating characteristic curves were also created for starter intake measured on the day of sampling, and over a 7-d period around sampling. In addition, based on the best combination of sensitivity and specificity, the optimal cut-point of circulating BHB on the day of sampling was $100 \mu \mathrm{mol} / \mathrm{L}$ of blood (data not shown). In contrast, the optimal cut-point of circulating BHB over a 7-d period around sampling was $150 \mu \mathrm{mol} / \mathrm{L}$ of blood (data not shown). As such, these cut-points can be used to predict average starter intake of $\geq 1,000 \mathrm{~g} / \mathrm{d}$ over $1 \mathrm{~d}$, a 3 -d period, or a 7 -d period. Because accurate measurement of starter intake is extremely laborious, and almost impossible in a group-housing system, the development and refinement of a surrogate measure to estimate starter grain intake would be welcomed and beneficial (Weary et al., 2009; Omidi-Mirzaei et al., 2015).

Test characteristics of sensitivity and specificity for Precision Xtra were determined for the assessment of adequate starter intake $(\geq 1,000 \mathrm{~g} / \mathrm{d})$, indicative of appropriate weaning age (Table 2 ). Again, specificity was 
Table 1. Test characteristics for laboratory BHB measured in micromoles per liter using a cut-off starter intake level of $\geq 1,000 \mathrm{~g} / \mathrm{d}$ measured over $1 \mathrm{~d}$, a 3 -d average, and a 7 -d average $(\mathrm{n}=120)$

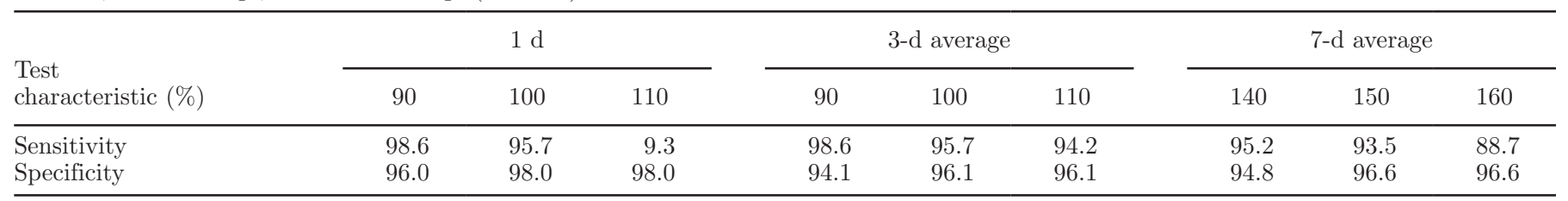

the test characteristic of greatest concern to minimize false positives. A value of $0.2 \mathrm{mmol} / \mathrm{L}$ on the Precision Xtra test yielded a sensitivity and specificity of 84.0 and $97.2 \%$, respectively, over the 3 -d average intake around the day of sampling. In comparison, a value of $0.1 \mathrm{mmol} / \mathrm{L}$ on the Precision Xtra test yielded a sensitivity and specificity of 100 and $72.6 \%$, respectively, over the 3 -d average. Similar findings were found on the day of sampling and over a 7-d period around sampling, as seen in Table 2. This finding suggests that because of the very high correlation between the Precision Xtra test and laboratory BHB, dairy producers can use either measure as a predictor of sufficient starter grain intake and rumen development to ascertain if the calf is ready to successfully transition from liquid to solid feed. From a practical standpoint, the Precision Xtra test is much more appealing than a laboratory test for BHB because it not only provides instantaneous onfarm results, but also at a fraction of the cost $(\geq 5-7$ times less expensive per test).

It should be noted that blood sampling in the current study occurred $2 \mathrm{~h}$ after initial delivery of solid feed. Blood BHB concentration in the calves in the current study (as shown in Eckert et al., 2015) were lower, at various similar ages, compared with that reported for calves in other studies where blood BHB was measured $3 \mathrm{~h}$ after initial solid feed delivery (Nemati et al., 2015; Omidi-Mirzaei et al., 2015). These findings would suggest that the cut-point for determining adequate starter intake may vary with time of blood sampling; further research where blood is sampled at multiple time points across the day is needed to confirm this relationship.

The results of this study demonstrate that the use of an instantaneous, calf-side test can be used in the decision-making process of determining sufficient starter grain intake at the time of weaning. The most practical application of such an on-farm test would be as a simple method of evaluating weaning programs by veterinarians or other advisors. This would be most useful on larger farms, as well as in situations where calves are group-housed, where individual solid feed consumption is not as easily tracked. In those situations, a sub-sample of calves could be tested, at the point of weaning, to determine if they are achieving sufficient starter intake to make a smooth transition; in cases where starter intake is insufficient, modifica-

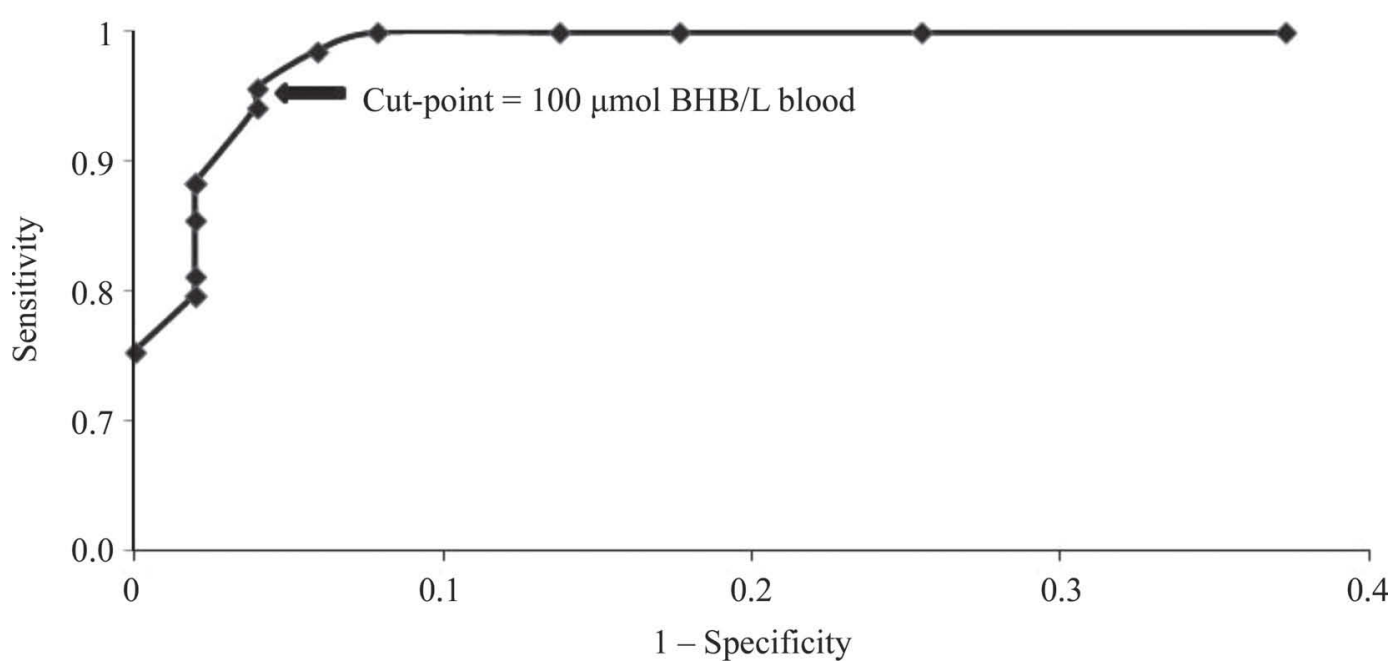

Figure 5. Receiver operating characteristic curve of the true positive rate against the false positive rate for different BHB values per liter of blood over a $3-d$ average period of starter intake $(n=120)$. 
Table 2. Test characteristics for the Precision Xtra ${ }^{1}$ test measured in millimoles per liter using a cut-off starter intake level of $\geq 1,000 \mathrm{~g} / \mathrm{d}$ measured over $1 \mathrm{~d}$, a 3 -d average, and a 7 -d average $(\mathrm{n}=200)$

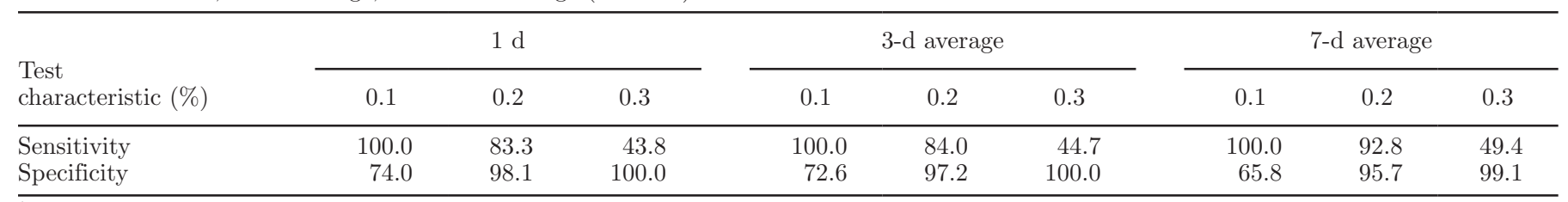

${ }^{1}$ Abbott Diabetes Care (Abingdon, UK).

tions to the weaning programs could be implemented to encourage greater starter intake by the time weaning occurs.

\section{CONCLUSIONS}

Laboratory BHB results were associated with starter intake, total ruminal VFA, ruminal butyrate, and BW. The optimal combination of sensitivity $(95.7 \%)$ and specificity (96.1\%) for circulating BHB to be predictive of a 3-d average period of starter intake of $1,000 \mathrm{~g} / \mathrm{d}$ was $100 \mu \mathrm{mol} \mathrm{BHB} / \mathrm{L}$ of blood, measured $2 \mathrm{~h}$ after morning feed delivery. Therefore, this cut-point can be used to predict adequate starter intake over a $3-\mathrm{d}$ period. A value of $0.2 \mathrm{mmol} / \mathrm{L}$ on the Precision Xtra test yielded a sensitivity and specificity of $84.0 \%$ and $97.2 \%$, respectively, over a 3 - $\mathrm{d}$ average of starter intake. The Precision Xtra whole blood BHB test conducted at calf-side was highly correlated with the laboratory BHB results, indicating that it is highly accurate, and shows promise for use in the decision-making process of determining sufficient starter grain intake and rumen development for successful transition from liquid to solid feed.

\section{ACKNOWLEDGMENTS}

The authors gratefully acknowledge the support of Christa Eckert and all staff at Eckerlea Acres Ltd. (Seaforth, ON, Canada). We are thankful for the financial support and donations provided by Nutreco Canada Inc. (Guelph, ON, Canada), Grober Nutrition (Cambridge, ON, Canada), and Nieuwland Feed and Supply Ltd. (Drayton, ON, Canada). We also appreciate the technical assistance provided by Vivianne Bielmann, Stephen Elgersma, and Julia Romagnoli of the University of Guelph (Guelph, ON, Canada).

\section{REFERENCES}

Baldwin, R. L., VI, K. R. McLeod, J. L. Klotz, and R. N. Heitmann. 2004. Rumen development, intestinal growth and hepatic metabolism in the pre- and postweaning ruminant. J. Dairy Sci. 87(E. Suppl.):E55-E65.
Bannink, A., J. France, S. Lopez, W. Gerrits, E. Kebreab, S. Tamminga, and J. Dijkstra. 2008. Modelling the implications of feeding strategy on rumen fermentation and functioning of the rumen wall. Anim. Feed Sci. Technol. 143:3-26.

Benschop, D. L., and J. P. Cant. 2009. Developmental changes in clearance of intravenous doses of glucose, acetate, and $\beta$-hydroxybutyrate from plasma of calves. Livest. Sci. 122:177-185.

Brown, R. E., C. L. Davis, J. R. Staubus, and W. O. Nelson. 1960 Production and absorption of volatile fatty acids in the perfused rumen. J. Dairy Sci. 43:1788-1797.

CCAC (Canadian Council on Animal Care). 2009. CCAC Guidelines On: The Care and Use of Farm Animals in Research, Teaching and Testing. CCAC, Ottawa, Canada.

Dijkstra, J., H. Boer, J. van Bruchem, M. Bruining, and S. Tamminga. 1993. Absorption of volatile fatty acids from the rumen of lactating dairy cows as influenced by volatile fatty acid concentration, pH and rumen liquid volume. Br. J. Nutr. 69:385-396.

Drackley, J. K. 2008. Calf nutrition from birth to breeding. Vet. Clin. North Am. Food Anim. Pract. 24:55-86.

Eckert, E., H. E. Brown, K. E. Leslie, T. J. DeVries, and M. A. Steele. 2015. Weaning age affects growth, feed intake, gastrointestinal development, and behavior in Holstein calves fed an elevated plane of nutrition during the preweaning stage. J. Dairy Sci. 98:6315-6326.

Gilliland, R. L., L. J. Bush, and J. D. Friend. 1962. Relation of ration composition to rumen development in early-weaned dairy calves with observations on ruminal parakeratosis. J. Dairy Sci. 45:1211-1217

Guerci, B., N. Tubiana-Rufi, B. Bauduceau, R. Bresson, A. Cuperlier, C. Delcroix, D. Durain, C. Fermon, J. P. Le Floch, C. LeDevehat, V. Melki, L. Monnier, H. Mosnier-Pudar, P. Taboulet, and H. Hanaire-Broutin. 2005. Advantages to using capillary blood betahydroxybutyrate determination for the detection and treatment of diabetic ketosis. Diabete Metab. 31:401-406.

Iwersen, M., U. Falkenberg, R. Voigtsberger, D. Forderung, and W. Heuwieser. 2009. Evaluation of an electronic cowside test to detect subclinical ketosis in dairy cows. J. Dairy Sci. 92:2618-2624.

Jeppesen, R., J. M. D. Enemark, and C. Enevoldsen. 2006. Ketone body measurement in dairy cows. Reference OS43-2 in Proc. 24th World Buiatrics Congress, Nice, France. World Assoc. Buiatrics, Vienna, Austria.

Khan, M. A., A. Bach, D. M. Weary, and M. A. G. von Keyserlingk. 2016. Invited review: Transitioning from milk to solid feed in dairy heifers. J. Dairy Sci. 99:885-902.

Khan, M. A., D. M. Weary, and M. A. G. von Keyserlingk. 2011. Invited review: Effects of milk ration on solid feed intake, weaning, and performance in dairy heifers. J. Dairy Sci. 94:1071-1081.

Lane, M. A., R. L. Baldwin VI, and B. W. Jesse. 2002. Developmental changes in ketogenic enzyme gene expression during sheep rumen development. J. Anim. Sci. 80:1538-1544.

Lane, M. A., R. L. Baldwin VI, and B. W. Jesse. 2000. Sheep rumen metabolic development in response to age and dietary treatments. J. Anim. Sci. 78:1990-1996.

Leighton, B., A. R. Nicholas, and C. I. Pogson. 1983. The pathway of ketogenesis in rumen epithelium of the sheep. Biochem. J. 216:769-772.

Mahrt, A.. O. Burfeind, and W. Heuwieser. 2014. Effects of time and sampling location on concentrations of $\beta$-hydroxybutyric acid in dairy cows. J. Dairy Sci. 97:291-298. 
Miller-Cushon, E. K., R. Bergeron, K. E. Leslie, and T. J. DeVries. 2013. Effect of milk feeding level on development of feeding behavior in dairy calves. J. Dairy Sci. 96:551-564.

Nemati, M., H. Amanlou, M. Khorvash, B. Moshiri, M. Mirzaei, M. A. Khan, and M. H. Ghaffari. 2015. Rumen fermentation, blood metabolites, and growth performance of calves during transition from liquid to solid feed: Effects of dietary level and particle size of alfalfa hay. J. Dairy Sci. 98:7131-7141.

Omidi-Mirzaei, H., M. Khorvash, G. R. Ghorbani, B. Moshiri, M. Mirzaei, A. Pezeshki, and M. H. Ghaffari. 2015. Effects of the step-up/step-down and step-down milk feeding procedures on the performance, structural growth, and blood metabolites of Holstein dairy calves. J. Dairy Sci. 98:7975-7981.

Overvest, M. A., R. Bergeron, D. B. Haley, and T. J. DeVries. 2016. Effect of feed type and method of presentation on feeding behavior, intake, and growth of dairy calves fed a high level of milk. J. Dairy Sci. 99:317-327.

Panousis, N., C. Brozos, I. Karagiannis, N. D. Giadinis, S. Lafi, and M. Kritsepi-Konstantinou. 2012. Evaluation of precision xceed ${ }^{\circledR}$ meter for on-site monitoring of blood $\beta$-hydroxybutyric acid and glucose concentrations in dairy sheep. Res. Vet. Sci. 93:435-439.

Pineda, A., and F. C. Cardoso. 2015. Technical note: Validation of a handheld meter for measuring $\beta$-hydroxybutyrate concentrations in plasma and serum from dairy cows. J. Dairy Sci. 98:8818-8824.
Quigley, J. D., III, Z. P. Smith, and R. N. Heitmann. 1991. Changes in plasma volatile fatty acids in response to weaning and feed intake in young calves. J. Dairy Sci. 74:258-263.

SAS Institute Inc. 2013. SAS Version 9.4. SAS Inst. Inc., Cary, NC.

Steele, M. A., L. Dionissopoulos, O. AlZahal, J. Doelman, and B. W. McBride. 2012. Rumen epithelial adaptation to ruminal acidosis in lactating cattle involves the coordinated expression of insulin-like growth factor-binding proteins and a cholesterolgenic enzyme. J. Dairy Sci. 95:318-327.

Warner, R. G., W. P. Flatt, and J. K. Loosli. 1956. Dietary factors influencing the development of the animal's stomach. J. Agric. Food Chem. 4:788-792.

Weary, D. M., J. M. Huzzey, and M. A. G. von Keyserlingk. 2009. Board-invited review: Using behavior to predict and identify ill health in animals. J. Anim. Sci. 87:770-777.

Williams, P. E. V., and A. J. Frost. 1992. Feeding the young ruminant. Pages 109-118 in Neonatal Survival and Growth. Occasional Publ. No. 15. M. Varley, P. E. V. Williams, and T. L. J. Lawrence, ed. Br. Soc. Anim. Prod., Edinburgh, UK.

Williamson, D. H., J. Mellanby, and H. A. Krebs. 1962. Enzymatic determination of $\mathrm{D}(-)-\beta$-hydroxybutyric acid and acetoacetic acid in blood. Biochem. J. 82:90-96. 